\section{Coughing Attacks as a Cause of Gastric Hemorrhage in Patients Who Have Undergone Percutaneous Endoscopic Gastrostomy: An Endoscopic Solution}

Percutaneous endoscopic gastrostomy (PEG) is a widely used procedure throughout the world with few complications [1]. In neurological disorders [2] which progress with persistent dysphagia, long-term enteral feeding by this method is needed.

A 48-year-old man diagnosed with multiple sclerosis 18 years earlier was admitted with severe dysphagia which resulted in the insertion of PEG for permanent feeding. A year after insertion, the patient experienced vomiting with blood. In the previous week the patient had suffered a respiratory infection with many coughing incidents.

Upper digestive endoscopy was carried out and an intussusception of a gastric fold into the orifice of the gastrostomy tube, coinciding with the coughing attacks, was detected; the prolapsed area had acquired a hypertrophic ischemic aspect with a redwine colour (Figure 1), and bled slightly upon touch. This dynamic phenomenon had been seen on various occasions, always coinciding with the coughing incidents, and was thus the cause of the digestive bleeding, given that no other wound was seen throughout the whole endoscopic exploration. In view of the observation of this phenomenon, resection of the affected area with a snare was carried out (Figure 2). After a year of follow up, there had been no more incidents of digestive bleeding and the endoscopic control showed no alterations.

Digestive haemorrhage is a rare complication of feeding via PEG, although gastric ulcers around the ostomy, caused by excessive tube traction, have been observed [4].

We had not previously encountered any similar occurrence, although the incidence at other sites of wounds causing digestive bleeding because of intussusception has been described [5]. The procedure required for the endoscopic solution was simple and a very common, standard clinical practice. It allowed us to provide a long-term satisfactory result, whilst maintaining feeding via PEG.

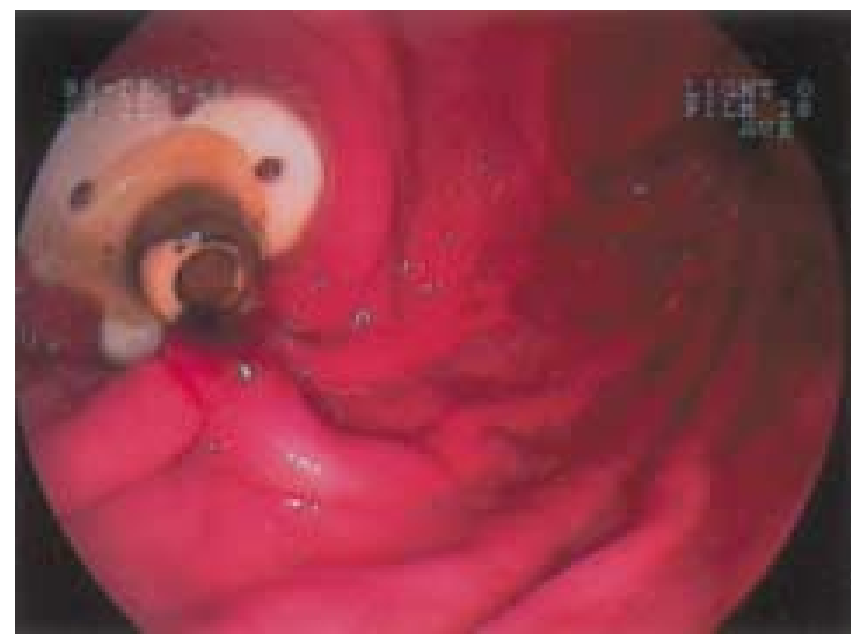

Figure 1 Intussusception of a gastric fold into the gastrostomy

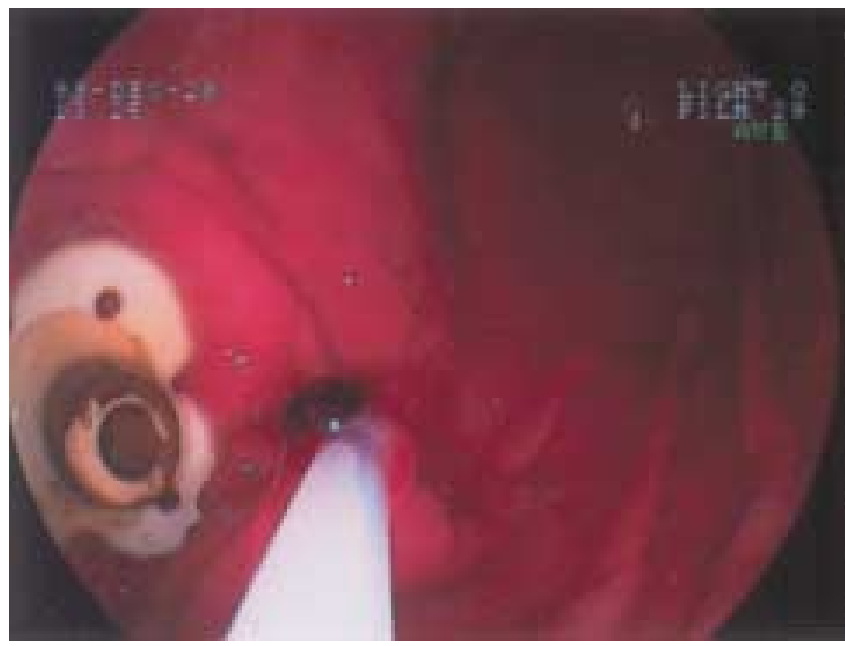

Figure 2 Snare resection and resolution of bleeding

J. L. Ulla, C. Almohalla, L. Ledo,

B. López Viedma, J. Vázquez-San Luis,

E. Vázquez-Astray

Digestive System Services,

Pontevedra Hospital Complex,

Pontevedra, Spain

\section{References}

${ }^{1}$ Panos MZ, Reilly H, Moran A, et al. Percutaneous endoscopic gastrostomy in a general hospital: prospective evaluation of indications, outcome, and randomised comparison of two tube designs. Gut 1994; 35: 1551-1556

${ }^{2}$ Park RH, Allison MC, Lang J, et al. Randomised comparison of percutaneous endoscopic gastrostomy and nasogastric tube feeding in patients with persisting neurological dysphagia. BMJ 1992; 304: 1406-1409

${ }^{3}$ Mellinger JD, Ponsky JL. Percutaneous endoscopic gastrostomy: state of the art. Endoscopy 1998; 30: 26-132
${ }^{4}$ Patel PH, Hunter W, Willis M, Thomas E. Upper gastrointestinal hemorrhage secondary to gastric ulcer complicating percutaneous endoscopic gastrostomy. Gastrointest Endosc 1988; 34: 88-289

${ }^{5}$ Miller LS, Barbarevech C, Friedman LS. Less frequent causes of lower gastrointestinal bleeding. Gastroenterol Clin N Am 1994; 23: 21-52

Corresponding Author

J. L. Ulla Rocha, M.D.

Digestive System Services

Pontevedra Hospital Complex

Pontevedra

Spain

Fax: + 34-986800077

E-mail: ullaroj1@terra.es 